\title{
Influence of aqueous chloride and bromide ions on bisphenol A degradation efficiency with zinc oxide nanoparticles
}

\author{
Yi-Chen Yang, Rama Shanker Sahu and Yang-hsin Shih ${ }^{*}$ (D)
}

\begin{abstract}
Zinc oxide (ZnO) nanoparticles (NPs) have been widely investigated for applications in photocatalytic degradation of organic pollutants in wastewater. Despite the advantages of robust ZnO material, its photocatalytic activity is greatly affected by environmental factors. Halogen ions are commonly found in wastewater, which directly affect the pollutant aggregation and sedimentation, therefore it is necessary to discuss their effect on the photocatalytic degradation. The current study assesses the halogen ions effect on the photocatalytic degradation of bisphenol A (BPA) using different dosage of sodium chloride ( $\mathrm{NaCl}$ ) and sodium bromide ( $\mathrm{NaBr}$ ). The microstructural characterization of ZnO NPs was conducted by transmission electron microscopy and hydrodynamic size was analyzed through dynamic light scattering. The effective BPA degradation with ZnO NPs was observed and pseudo-first-order kinetics was calculated. The increase of $\mathrm{ZnO}$ NPs dosage from 10 to $100 \mathrm{mg} \mathrm{L}^{-1}$ enhanced the degradation rate constant of BPA up to 0.089 $\mathrm{min}^{-1}$ (14.8 folds). In order to evaluate the role halogen ions to degrade BPA, $\mathrm{NaBr}$ and $\mathrm{NaCl}$ were used. The degradation rate was reduced to $0.0034 \mathrm{~min}^{-1}$ after the addition of $\mathrm{NaBr}$ due to the increase in hydrodynamic particle size, thereby restricting the light adsorption capacity. Noteworthy, upon addition of $\mathrm{NaCl}$ up to $500 \mathrm{mM}$ concentration, only a slight decrease on BPA degradation rate was observed. Therefore, this study unveils the role of chloride ions as an effective medium for BPA degradation by ZnO NPs, without aggregation, and provides a novel platform for the treatment of organic pollutants in saline water.
\end{abstract}

Keywords: BPA, Zinc oxide, Photocatalytic degradation, Inorganic ion, Hydrodynamic particle size

\section{Introduction}

World-wide contamination of phenolic compounds in aquatic environmental has attracted increasing attentions in the research society. Bisphenol A (BPA) used as basic monomer in the synthesis of brominated flame retardants, epoxy resins and polycarbonates due to which it became the highest produced chemical worldwide [1]. However, their characteristics, environmental distribution and adverse effect on human health remain lessknown compared to conventional pollutants with the worldwide demand dramatically increasing [2]. BPA is one of the endocrine disruptors due to its genotoxic and

\footnotetext{
* Correspondence: yhs@ntu.edu.tw

Department of Agricultural Chemistry, National Taiwan University, Taipei 106, Taiwan
}

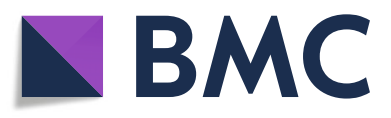

( ) The Author(s). 2022 Open Access This article is licensed under a Creative Commons Attribution 4.0 International License, which permits use, sharing, adaptation, distribution and reproduction in any medium or format, as long as you give

appropriate credit to the original author(s) and the source, provide a link to the Creative Commons licence, and indicate if changes were made. The images or other third party material in this article are included in the article's Creative Commons licence, unless indicated otherwise in a credit line to the material. If material is not included in the article's Creative Commons licence and your intended use is not permitted by statutory regulation or exceeds the permitted use, you will need to obtain permission directly from the copyright holder. To view a copy of this licence, visit http://creativecommons.org/licenses/by/4.0/. brain development [3]. Owning to the discharge of wastewater and improper accumulation of solid waste, BPA has been ubiquitous in the environment [4]. In some rivers, BPA concentration could even reach up to $8 \mu \mathrm{g} \mathrm{L}^{-1}$ [5], and the report from Barboza et al. [6] also revealed the present of BPA and its analogs in muscle and liver of fish. In China, up to $144 \mathrm{ng} \mathrm{mL}^{-1}$ of bisphenol analogues was detected in serum samples from pregnant women [7]. Since even low concentration of BPA causes hazardous health, the development of treatment techniques with high efficiency is required.

Treatment of contaminated wastewater has received increasing attention. Several techniques such as chemical oxidation [8], sono-photo-Fenton oxidation [9], UV- 
assisted chemical oxidation [10], electrochemical degradation [11], zerovalent metal-based reduction [12], biodegradation [13], and adsorption methods [14] were studied. Chemical oxidation method has been widely used for wastewater treatment including Fenton process [15] and ozone treatment [16] process, which could effectively oxidize the organic contaminants in the wastewater. Nanoscale zero valent iron (NZVI) has appropriate redox potential to reduce organic contaminant $[17,18,19]$ under anaerobic conditions but cannot totally mineralize the contaminant due to its losing reducing activity and quick oxidation when exposed in the air. Previous studies reported that BPA is biodegradable by bacterial strains [20], while it takes at least several days to remove BPA and produces byproducts. Activated carbon is commonly used for adsorption of compounds in air or aquatic system and the adsorption capacity depends on the carbon used and the characteristic of wastewater [21, 22]. Physical adsorption is cost effective treatment procedure [23] but the contaminated adsorbent requires further treatment and proper disposal. Various studies suggest that chemical reduction, advanced oxidation and electrochemical processes are desired and effective treatment procedure for BPA, which could be activated by using expensive and noble metal catalysts [24]. Park et al. have demonstrated improved photocatalytic degradation of BPA in the presence of silver nanoparticles (NPs) immobilized with polyvinyl alcohol and activated by low hydrogen peroxide $\left(\mathrm{H}_{2} \mathrm{O}_{2}\right)$ concentration [25]. The quick dissolution of silver NPs was also reported due to the presence highly reactive $\mathrm{H}_{2} \mathrm{O}_{2}$ in the solution. NZVI has been exploited in last 4 decades for wastewater treatment but agglomeration due to intrinsic magnetic properties and quick aerial oxidation of NZVI remain the major challenges [26].

The natural phenomenon involves the direct photocatalytic degradation of organic chemicals in the environment. The photocatalysis is the most convenient method for the treatment of wastewater due to its facile procedure, inexpensive operational cost, high degradation efficacy facilitated by reactive oxygen species generated during the reaction. In this regard, zinc oxide $(\mathrm{ZnO}) \mathrm{NPs}$, an environmentally benign material has been used for photocatalytic degradation of organic pollutants from wastewater. $\mathrm{ZnO}$ NPs have attained the huge acceptance for environmental applications because of their remarkable optical properties, electron affinity, high redox potential, environmentally benign, and relatively low cost $[27,28]$. The commercial or chemically modified $\mathrm{ZnO}$ NPs have demonstrated substantial differences in their morphology, shape and size, and photoelectric properties which show important role in the optical properties and photoactivity of $\mathrm{ZnO}$ NPs. However, previous studies showed that the effect of environmental factors such as $\mathrm{pH}$, inorganic ions [29, $30,31]$ and organic compounds are important and needed to be considered in the $\mathrm{ZnO}$ NPs photocatalytic degradation process. Wang et al. have uncovered the influence of different inorganic ions $\left(\mathrm{PO}_{4}^{-}, \mathrm{SO}_{4}{ }^{-2}, \mathrm{CO}_{3}{ }^{-}\right)$ on the degradation of $\mathrm{BPA}$ in the presence of $\mathrm{ZnO} \mathrm{NPs}$, in which $\mathrm{PO}_{4}{ }^{-}$ions restricted the BPA degradation to $10 \%$ [32]. It was observed that the adsorption of the dyes onto the surface of $\mathrm{ZnO}$ NPs is strongly influenced by the $\mathrm{pH}$ of the solution due to the surface charge of both $\mathrm{ZnO}$ NPs and contaminants [33]. The effect of inorganic ions on $\mathrm{ZnO}$ photocatalytic degradation has been widely reported, yet whether the addition of inorganic ions can increase or decrease degradation efficiency is still unsure in different conditions. Lee et al. [34] demonstrated the role of various inorganic species such as $\mathrm{BrO}_{3}{ }^{-}, \mathrm{S}_{2} \mathrm{O}_{8}{ }^{2-}$ and $\mathrm{SO}_{3}{ }^{-}$could be advantageous to enhance the photocatalytic degradation of organic contaminants in the presence of $\mathrm{ZnO}$ NPs. However, some inorganic ions such as $\mathrm{Cl}^{-}, \mathrm{NO}_{3}{ }^{-}$and $\mathrm{CO}_{3}{ }^{2-}$ tend to retard the photocatalytic degradation of $\mathrm{ZnO}$ NPs. The anions have been known to be $\mathrm{OH}$ radical and photo-hole scavengers, strong reactive species for BPA degradation. In addition, the cations including $\mathrm{Na}^{+}, \mathrm{K}^{+}$, and $\mathrm{Ca}^{+}$slightly inhibit the BPA degradation by reducing the electrical double layer to enhance the ZnO NPs aggregation [35]. Therefore, it is noteworthy to evaluate the performance of $\mathrm{ZnO}$-based photocatalysts in the presence of inorganic ions in the wastewater during the photocatalytic treatment process.

The current study demonstrates the effect of inorganic ions on the photocatalytic degradation of BPA using $\mathrm{ZnO}$ NPs under UV light irradiation. The effect of $\mathrm{ZnO}$ NPs dosages on photocatalytic degradation of BPA was investigated to optimize the optimum catalyst dose. The experiments under the influence of different inorganic ion concentrations $(\mathrm{NaCl}$ and $\mathrm{NaBr})$ were performed and the change in hydrodynamic particle sizes were also monitored. The relationship among inorganic ion concentration, $\mathrm{ZnO}$ particle size and reaction kinetics is discussed.

\section{Materials and methods}

\subsection{Materials}

The commercial ZnO NPs powder (Uniregion Biotech) with particle size of $20 \mathrm{~nm}$ was used in the experiments. Bisphenol A (CAS No. 80-05-7), sodium chloride and sodium bromide in this research were obtained from Acros Organics. All solutions were prepared with ultrapure water and used without further purification.

\subsection{Characterization of ZnO NPs analysis}

The crystal patterns of the ZnO NPs were measured by Bruker D8 Advanced X-ray diffractometer (XRD) with 
$\mathrm{Cu}-\mathrm{K} \alpha$ radiation (Ni filtered, $\lambda=1.5405 \AA$, at voltage 40 $\mathrm{kV}$ and current $40 \mathrm{~mA}$ ). The morphology of $\mathrm{ZnO}$ NPs was analyzed by transmission electron microscopy (TEM). NPs suspension was prepared using desired $\mathrm{ZnO}$ NPs concentrations and ultrasonicated for $10 \mathrm{~min}$ at room temperature. DELTA ultrasonic cleaning machine, $\mathrm{DC} 150 \mathrm{H} / 150 \mathrm{~W}$ was used for homogenous suspension. The hydrodynamic particle size of ZnO NPs and their distributions were measured by a dynamic light scattering (DLS) instrument (Zetasizer nano ZS, Malvern nano series V6.0). UV-Vis spectra was used to record the light absorption property of $\mathrm{ZnO}$ NPs under the wavelength between 200 to $800 \mathrm{~nm}$. The sedimentation of those large agglomerates of $\mathrm{ZnO}$ NPs was also monitored with UV-Vis spectra at $365 \mathrm{~nm}$ in $90 \mathrm{~min}$. High performance liquid chromatography (HPLC, Agilent 1200 series) equipped with C-18 column, auto-injector, and variable wavelength detector was used to analyze the concentration of BPA in the experiments.

\subsection{Photocatalytic degradation experiments}

The typical photocatalytic experiments were conducted in the laboratory. A photochemical reactor was equipped with $4 \times 8$-W UV lamps at the irradiation wavelength of $365 \mathrm{~nm}$. Experimental solutions in $30 \mathrm{~mL}$ tubes were placed in a rotor inside the photochemical reactor to irradiate them equally. In degradation experiments, $25 \mathrm{~mL}$ solution that contained different ZnO NPs photocatalyst dosages (10$100 \mathrm{~m} \mathrm{~L}^{-1}$ ) and $5 \mathrm{ppm} \mathrm{BPA}$ was prepared to conduct the experiments. After 30-min dark adsorption experiment, the solutions were illuminated under the light at the irradiation wavelength of $365 \mathrm{~nm}$. All the experiments were performed in $100 \mathrm{mg} \mathrm{L}^{-1} \mathrm{ZnO}$ NPs dose, 5 ppm BPA conc., and neutral $\mathrm{pH}$ at room temperature until unless mentioned. During the experiment, the aliquot of $2 \mathrm{~mL}$ was collected, filtered through $0.22-\mu \mathrm{m}$ filter and the concentration of BPA was analyzed by HPLC through auto-injector at selected intervals. In addition, Coumarin has been employed to detect $\mathrm{OH}$ radicals during the photocatalytic degradation of BPA. The fluorescence probe compound (coumarin) was used which upon reaction with $\cdot \mathrm{OH}$ radicals generated byproduct (7-hydroxycoumarin), measured by photoluminescence, as described in the literature [36]. In brief, $0.1 \mathrm{mM}$ coumarin solution was taken as blank and desired amount of $\mathrm{ZnO}$ NPs was dispersed in the dark under continuous stirring. The aqueous solution was then exposed to UV light and aliquots were withdrawn at specific time intervals and filtered immediately. The obtained solution was then analyzed by fluorescence spectrophotometer (Hitachi, F-7000 FL spectrophotometer).

\subsection{Chloride and bromide ions effect}

$\mathrm{NaCl}$ and $\mathrm{NaBr}$ were used as inorganic ions under specific dosage of $\mathrm{ZnO}$ NPs to evaluate BPA degradation in the following experiments. Different chloride or bromide ion concentrations (0 to $500 \mathrm{mM}$ ) were used for BPA degradation process. Before performing the experiments, the inorganic ions and $\mathrm{ZnO}$ NPs were added to the solution containing $5 \mathrm{ppm} \mathrm{BPA}$, stirred for $1 \mathrm{~min}$ and kept in the dark for $30 \mathrm{~min}$ to attain adsorption and desorption equilibrium before the photocatalytic degradation. The reaction solution was later exposed to UV light to observe the photocatalytic efficiency of ZnO NPs. The aliquot of $2 \mathrm{~mL}$ was collected, filtered through $0.22-\mu \mathrm{m}$ filter and analyzed by HPLC through auto-injector at desired intervals. DLS and $\mathrm{pH}$ analysis were also carried out after every batch of experiment.

\section{Results and discussion}

\subsection{Morphological characterization of ZnO NPs}

The crystal patterns of $\mathrm{ZnO}$ NPs were analyzed by XRD as displayed in Fig. 1a. Various crystal patterns of $\mathrm{ZnO}$ NPs with high relative intensity have been observed at

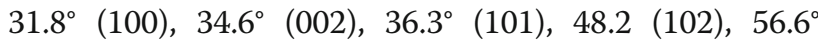
(110), $62.6^{\circ}$ (103), and $68.7^{\circ}$ (112), consistent with JCPDS No. 36-1451 [32]. The TEM image of ZnO NPs in Fig. $1 \mathrm{~b}$ demonstrates the clear particle distribution and also the formation of small clusters. However, due to the high surface potentials of $\mathrm{ZnO} N P s$, they aggregate when store for long time and need further dispersion before every experiment. ZnO NPs aggregate to form big agglomerates and the particle sizes can approach microscale, when suspended in DI water. $\mathrm{ZnO}$ NPs aggregation was further analyzed by DLS (Fig. 1c), depicts the average particle size of ZnO NPs in water is about $250 \mathrm{~nm}$ after sonication. Many studies applied ultrasonication to suspend NPs in aqueous solution before experiments [37]. Therefore, $\mathrm{ZnO}$ NPs suspensions used in experiments was allowed for $30 \mathrm{~min}$ ultrasonication in advance to properly disperse NPs. The full-scale UV-Vsible spectra of $\mathrm{ZnO}$ NPs were obtained as depicted in Fig. 1d to confirm the light absorption range $(365 \mathrm{~nm})$, which is corresponding to a broad band gap $(3.39 \mathrm{eV})$ in Choi et al.'s report [38].

\subsection{Photocatalytic degradation of BPA}

The photocatalytic degradation of $5 \mathrm{ppm}$ BPA was performed by varying the dosage of $\mathrm{ZnO}$ NPs from 10 to $100 \mathrm{mg} \mathrm{L}^{-1}$ under $365 \mathrm{~nm}$ UV light (Fig. 2a). The degradation rate constants $(\mathrm{k})$ were determined by a pseudo-first-order rate kinetics $[39,40]$ :

$$
C=C_{0} e^{-k t}
$$

where $C$ is the concentration of BPA after time $\mathrm{t}, C_{O}$ is the initial concentration of BPA, $t$ is the reaction time, and $k$ is the pseudo-first-order rate kinetics. 

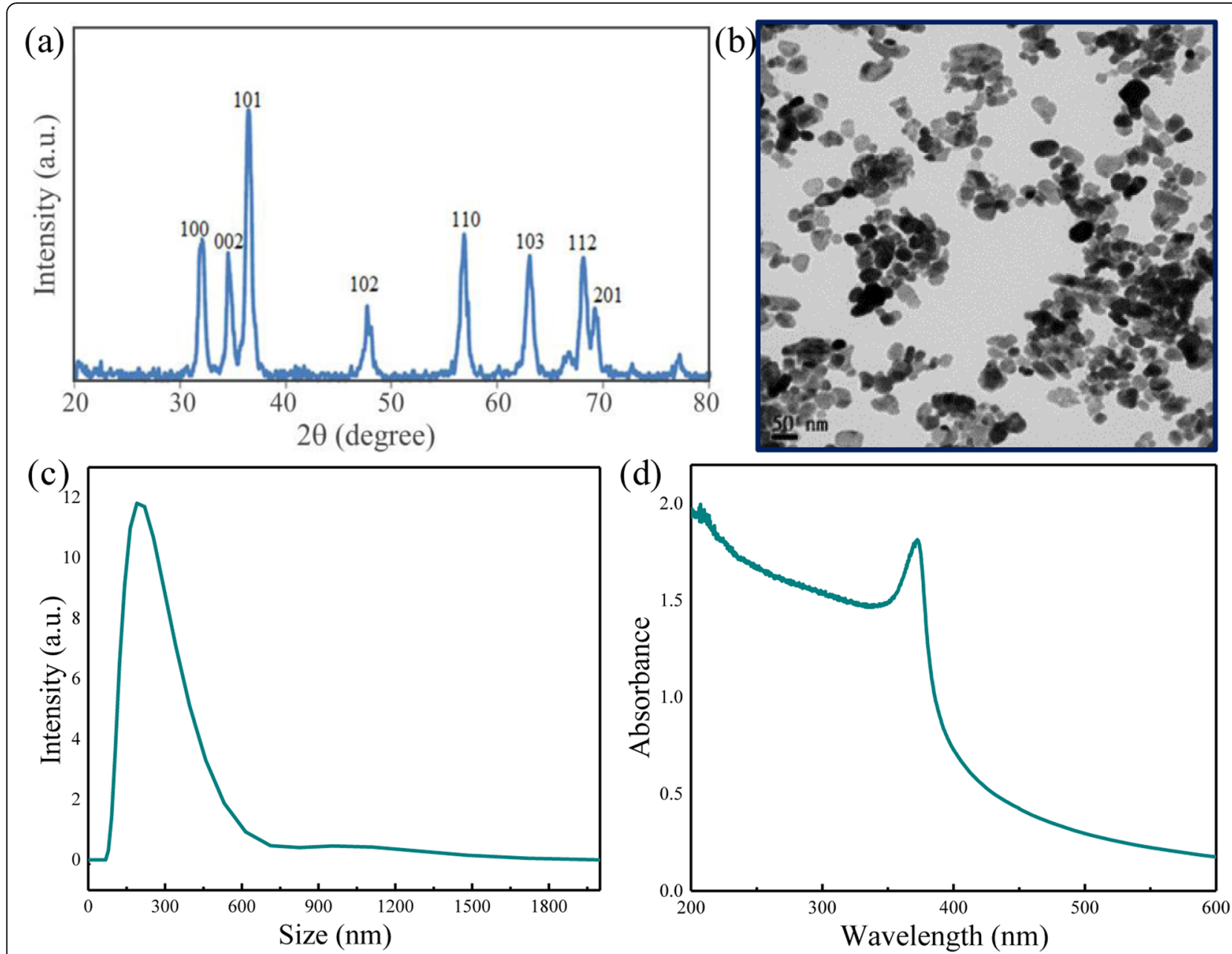

Fig. 1 (a) XRD pattern, (b) The TEM image, (c) DLS size distribution, and (d) full scan UV-Visible spectra of ZnO NPs

The photocatalytic degradation rate can be properly described by pseudo-first-order kinetics under different $\mathrm{ZnO}$ NPs dosages. Enhanced rate of BPA was observed when $\mathrm{ZnO}$ NPs dose increased from 10 to $100 \mathrm{mg} \mathrm{L}^{-1}$ $\left(0.006\right.$ to $\left.0.089 \mathrm{~min}^{-1}\right)$. Previous studies also indicated that photocatalytic degradation rates of NPs on organic contaminants can be described by pseudo-first-order kinetics [41, 42]. The enhancement of the degradation rate of BPA was observed with the increase of $\mathrm{ZnO}$ NPs dosage from $10 \mathrm{mg}$ to $100 \mathrm{mg} \mathrm{L}^{-1}$, owning to the increase in the concentration of catalyst and adsorption sites on ZnO NPs surface. The result of full scan also showed that the fraction of UV light absorbed by the catalyst increased as the concentration of ZnO NPs increased in a suspension (Fig. 2b). Therefore, $100 \mathrm{mg} \mathrm{L}^{-1}$ $\mathrm{ZnO}$ NPs catalyst dose was used during entire photocatalytic experiments. Previous studies indicate that $\mathrm{OH}$ radicals and positive holes play the major role in $\mathrm{ZnO}$ photocatalytic degradation process $[43,44]$. Owing to the increased yield of $\mathrm{OH}$ radicals as the dosage of $\mathrm{ZnO}$
NPs increased, the proportion of reactive oxygen species that attack BPA and its intermediates increases. There was no significant adsorption was observed when the dosage of $\mathrm{ZnO}$ NPs was 20,50 and $100 \mathrm{mg} \mathrm{L}^{-1}$, while the removal of 7\% BPA by $100 \mathrm{mg} \mathrm{L}^{-1} \mathrm{ZnO}$ NPs was observed in the first 30 min under dark condition. Considering of economic efficiency, the following experiments were performed with the dosage of $100 \mathrm{mg} \mathrm{L}^{-1} \mathrm{ZnO}$ NPs. The linear relationship between $\mathrm{ZnO}$ NPs concentration (10-100 $\left.\mathrm{mg} \mathrm{L}^{-1}\right)$ and $k_{o b s}$ (pseudo-first-order rate constant) can be observed. Figure 2c shows the rate of BPA enhances as catalyst dose increased from $10 \mathrm{mg} \mathrm{L}^{-1}$ $\left(0.006 \mathrm{~min}^{-1}\right)$ to $100 \mathrm{mg} \mathrm{L}^{-1}$ (0.089 $\left.\mathrm{min}^{-1}\right)$, suggesting the degradation of BPA is catalyst dose dependent. The reusability and stability of $\mathrm{ZnO}$ NPs have been analyzed by performing 3-consecutive BPA degradation cycles (Fig. 2d). $100 \mathrm{mg} \mathrm{L}^{-1}$ of $\mathrm{ZnO}$ NPs dispersed in the BPA $(5 \mathrm{ppm})$ solutions under similar reaction conditions for reusability test. The sample aliquots were collected at selected time intervals during entire experiment. The 

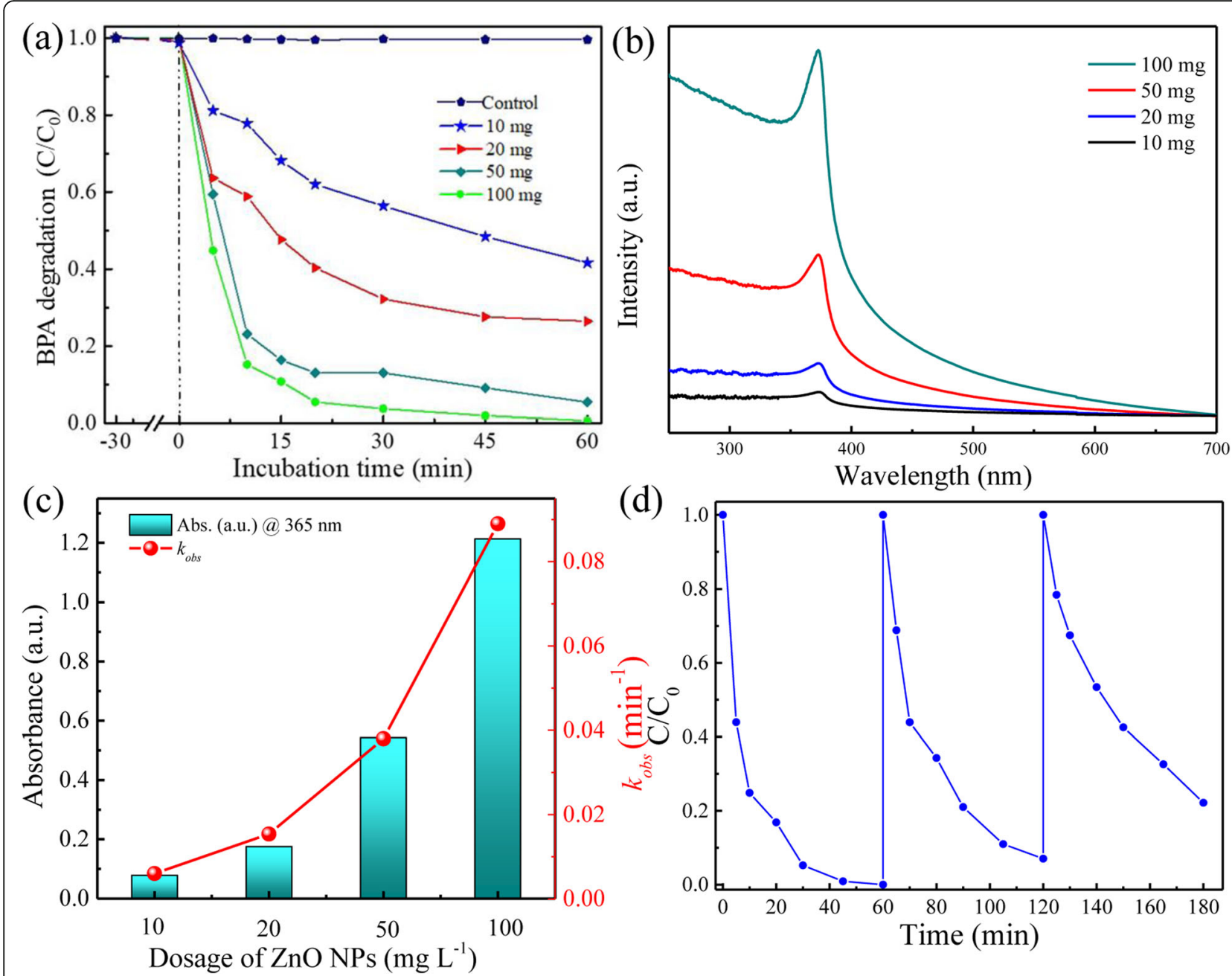

Fig. 2 (a) Effect of the initial ZnO NPs catalyst loading (10-100 $\mathrm{mg} \mathrm{L}^{-1}$ ) on the photocatalytic degradation of BPA (5 ppm) under $365 \mathrm{~nm}$ UV light $(4 \times 8$-W tube light), $\mathrm{pH} 7$ at room temperature, (b) full scan UV-visible spectra after different ZnO NPs loading, (c) linear relationship between $\mathrm{ZnO}$ concentration catalyst dose and UV absorption, and (d) reusability and stability test

initial BPA concentration was maintained to 5 ppm after each photocatalytic cycle. Slight decrease in the photocatalytic rate was observed after 3 repeated cycles, suggest that $\mathrm{ZnO}$ NPs can be utilized for BPA degradation repeatedly more than one cycle.

The $\cdot \mathrm{OH}$ radicals generated during BPA degradation were measured by PL probe method using coumarin. 100 $\mathrm{mg} \mathrm{ZnO}$ NPs were dispersed in $0.1 \mathrm{mM}$ coumarin solution and stirred under dark for $30 \mathrm{~min}$ before UV light illumination. The photogenerated 7-hydroxycoumarin compound were then collected and analyzed measuring PL signals. The excitation wavelength was set at $332 \mathrm{~nm}$ and scan range was selected between 380 to $600 \mathrm{~nm}$ with the scanning speed of $240 \mathrm{~nm} \mathrm{~min}^{-1}$. Figure 3a shows the different PL curves of the solution obtained at different time period. The PL signal intensity increases as time increases, suggesting the formation of $\mathrm{OH}$ radicals in the solution. The change in fluorescence intensity $(\% \Delta \mathrm{F})$ respective to time was analyzed and shown in Fig. 3b. the linear curve of fluorescence intensity change suggesting that $\mathrm{ZnO}$ NPs exposure under UV light generates $\cdot \mathrm{OH}$ radicals, which are responsible for BPA degradation. Our previous study demonstrates the enhanced photocatalytic BPA mineralization by metal-free graphitic carbon nitride was achieved due to the formation of $\mathrm{OH}$ radical, and byproducts were identified by high-resolution electrospray ionization mass spectrometry analysis [45].

\subsection{The effect of chloride ions on photocatalytic degradation of BPA}

The effect of different $\mathrm{NaCl}$ concentrations on the photocatalytic degradation process of BPA in the presence of $\mathrm{ZnO}$ NPs was evaluated. Figure 4a shows the increase of $\mathrm{NaCl}$ concentration resulting in slower BPA removal; the degradation rate constant was decreased around $50 \%$ by $500 \mathrm{mM} \mathrm{NaCl}$. The BPA rate constants 

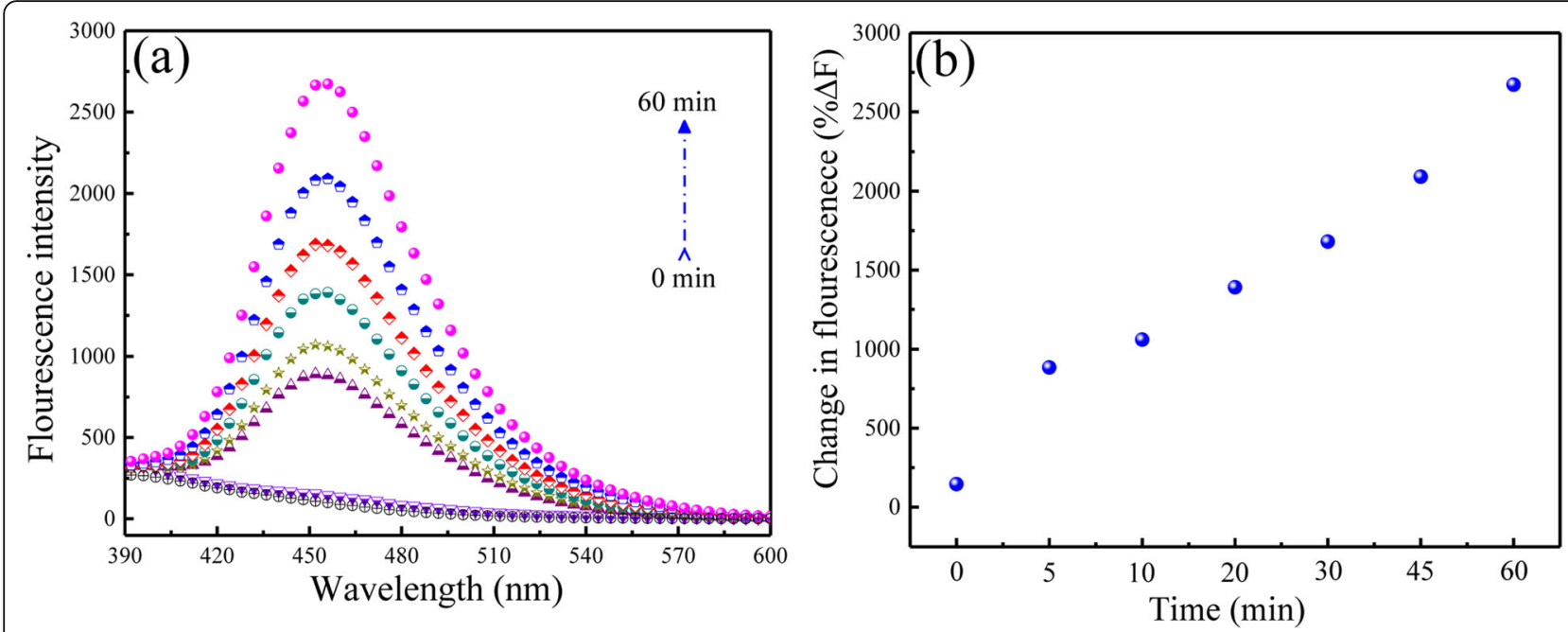

Fig. 3 (a) PL spectra of ZnO NPs at different time intervals, and (b) change in fluorescence intensity with time

were calculated $0.089,0.038,0.035$ and $0.032 \mathrm{~min}^{-1}$ for $0,10,100$ and $500 \mathrm{mM} \mathrm{NaCl}$, respectively (Fig. $4 \mathrm{~b}$ and Table 1). The previous studies reported that in the presence of inorganic ions, the compression of the electrostatic double layer of NPs occurs, causing particle aggregation, decrease of surface area and therefore the decline of the photocatalytic degradation activity [46, 47]. The effect of $\mathrm{NaCl}$ on $\mathrm{ZnO} \mathrm{NPs}$ was investigated and observed the absorbance change over time. The average hydrodynamic particle size of $\mathrm{ZnO}$ NPs after degradation experiments were determined by UV-Visible spectra and DLS. Furthermore, ZnO NPs sedimentation was also observed in the presence of various $\mathrm{NaCl}$ concentrations. The absorbance decreased up to $32 \%$ when $\mathrm{NaCl}$ concentration increased to $500 \mathrm{mM} \mathrm{NaCl}$ concentration after 90 min sedimentation time (Fig. 5a). On the other hand, the average hydrodynamic particle sizes were 1240, 1421, 1330 and $1265 \mathrm{~nm}$ for $0,10,100$, and $500 \mathrm{mM}$ addition of $\mathrm{NaCl}$, respectively (Fig. $5 \mathrm{~b}$ and Table 1). The decreasing trend of the absorbance of $\mathrm{ZnO}$ NPs indicated the settlement of ZnO NPs with the increasing of $\mathrm{NaCl}$ concentration. However, there was no significant enhancement in the aggregation behavior showed in DLS result when the addition of $\mathrm{NaCl}$ concentration increased up to $500 \mathrm{mM}$, which was consistent with the result of absorbance change and the slightly suppression on degradation rate constants. The dual effect of $\mathrm{NaCl}$ on photocatalytic degradation was also observed by Liu et al. [48]. Chloride ions could enhance or suppress the degradation of Acid Orange 7 in different
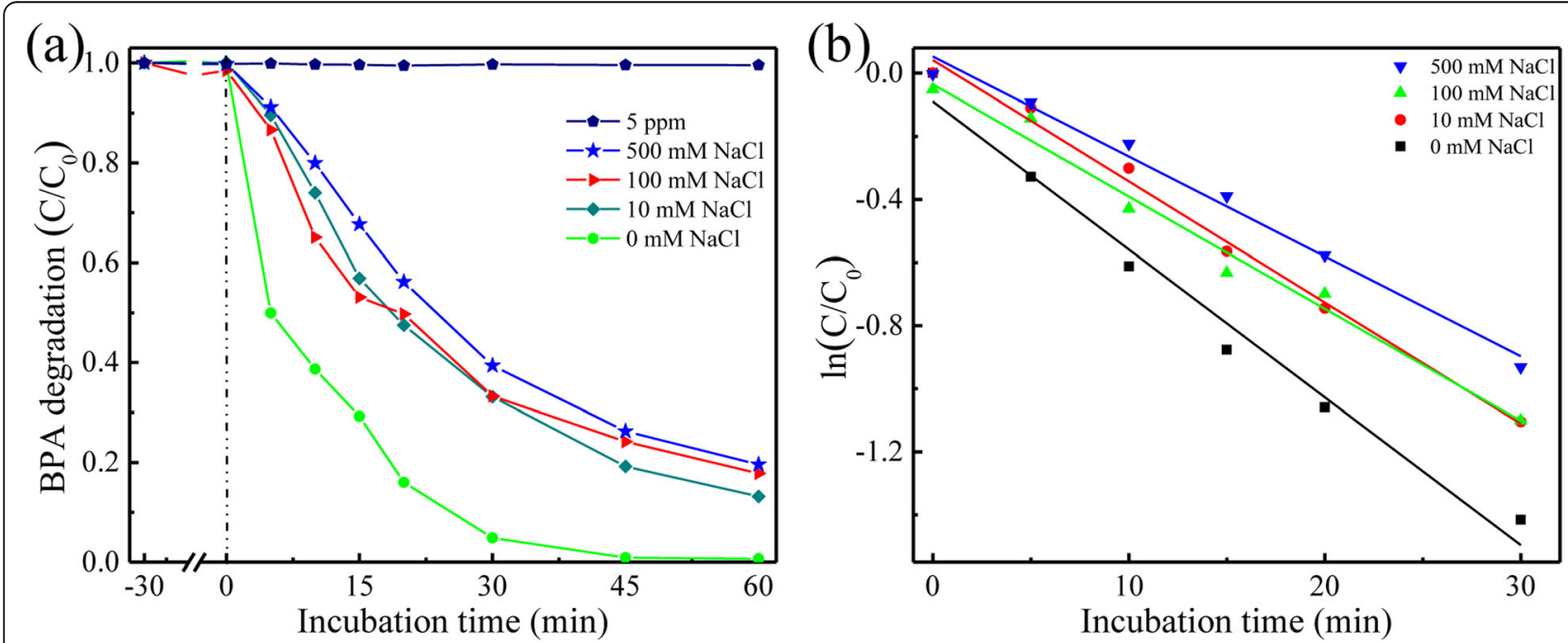

Fig. 4 (a) Effect of the $\mathrm{NaCl}$ concentration on the photocatalytic degradation of BPA with ZnO NPs under $365 \mathrm{~nm}$ UV light, (b) the plot of In (C/ Co) vs irradiation time for the photocatalytic degradation of BPA with ZnO NPs under different $\mathrm{NaCl}$ concentrations 
Table 1 Effect of $\mathrm{NaCl}$ and $\mathrm{NaBr}$ on the observed rate constant $\left(\mathrm{min}^{-1}\right)$, final average particle size (nm) measured by DLS, and the final $\mathrm{pH}$

\begin{tabular}{lllll}
\hline & Salt dosage $(\mathbf{m M})$ & Kinetic constant $\left(\mathbf{m i n}^{-\mathbf{1}}\right)$ & Final particle size $(\mathbf{n m})$ & Final pH \\
\hline $\mathrm{NaCl}$ & 0 & 0.089 & 1240 & 6.70 \\
& 10 & 0.046 & 1421 & 6.95 \\
& 100 & 0.038 & 1330 & 7.2 \\
& 500 & 0.032 & 1265 & 7.45 \\
$\mathrm{NaBr}$ & 0 & 0.089 & 1240 & 6.70 \\
& 10 & 0.0076 & 1935 & 6.75 \\
& 100 & 0.0053 & 2399 & 6.98 \\
& 500 & 0.0038 & 2115 & 6.85 \\
\hline
\end{tabular}

*Initial reaction $\mathrm{pH} 6.7$

systems [49]. The higher $\mathrm{NaCl}$ concentration $(>50 \mathrm{mM})$ is beneficial to increase the amount of reactive chlorine species, while the dye photocatalytic degradation rate decreased with low $\mathrm{NaCl}$ concentration $(<10 \mathrm{mM})$, signifying that the concentration impacts the effect of $\mathrm{NaCl}$ on the photocatalytic degradation [50].

\subsection{The effect of sodium bromide on photocatalytic degradation of BPA}

Experiments of different $\mathrm{NaBr}$ concentration on the photocatalytic degradation performances of $\mathrm{ZnO}$ on BPA was carried out and shown in Fig. 6a. Upon addition of $\mathrm{NaBr}$ from 10 to $500 \mathrm{mM}$ concentration, the degradation of BPA was found to be suppressing, suggesting a reaction constraining effect. This inhibition could be due to the competition between BPA molecules and bromide ions on the active sites of the catalysts. The photogenerated rate constants were 0.089, 0.0076, 0.0053 and $0.0038 \mathrm{~min}^{-1}$ for $0,10,100$ and $500 \mathrm{mM}$ $\mathrm{NaBr}$ addition, respectively (Fig. $6 \mathrm{~b}$ and Table 1 ). The suppression effect of $\mathrm{NaBr}$ on BPA degradation was noticeably seen, which was in the following sequence $10>$ $100>500 \mathrm{mM}$. In order to observe the hydrodynamic changes of the ZnO NPS, which may affect the surface area and active sites, the DLS study was conducted. The results clearly showed the increase of the average hydrodynamic size of $\mathrm{ZnO}$ NPs after the addition of $\mathrm{NaBr}$. The sedimentation curve of solution indicates the aggregation of $\mathrm{ZnO} \mathrm{NPs}$, which could be the reason for the suppression of BPA degradation reaction (Fig. 7a). Further, the average hydrodynamic size of $\mathrm{ZnO}$ NPs was found to be $1240 \mathrm{~nm}$ for $0 \mathrm{mM} \mathrm{NaBr}, 1935 \mathrm{~nm}$ for 10 $\mathrm{mM} \mathrm{NaBr}, 2399 \mathrm{~nm}$ for $100 \mathrm{mM} \mathrm{NaBr}$ and $2115 \mathrm{~nm}$ for $500 \mathrm{mM} \mathrm{NaBr}$ (Fig. 7b and Table 1). These results show that the BPA photocatalytic degradation depends on the ion concentration. The presence of $\mathrm{NaCl}$ and $\mathrm{NaBr}$ also causes the salting-out effect, resulting in the insolubility of BPA, hence decrease the photocatalytic degradation [51]. Garcia-Espinoza et al. [52] demonstrated the striking effect of halide ions for dye degradation due to

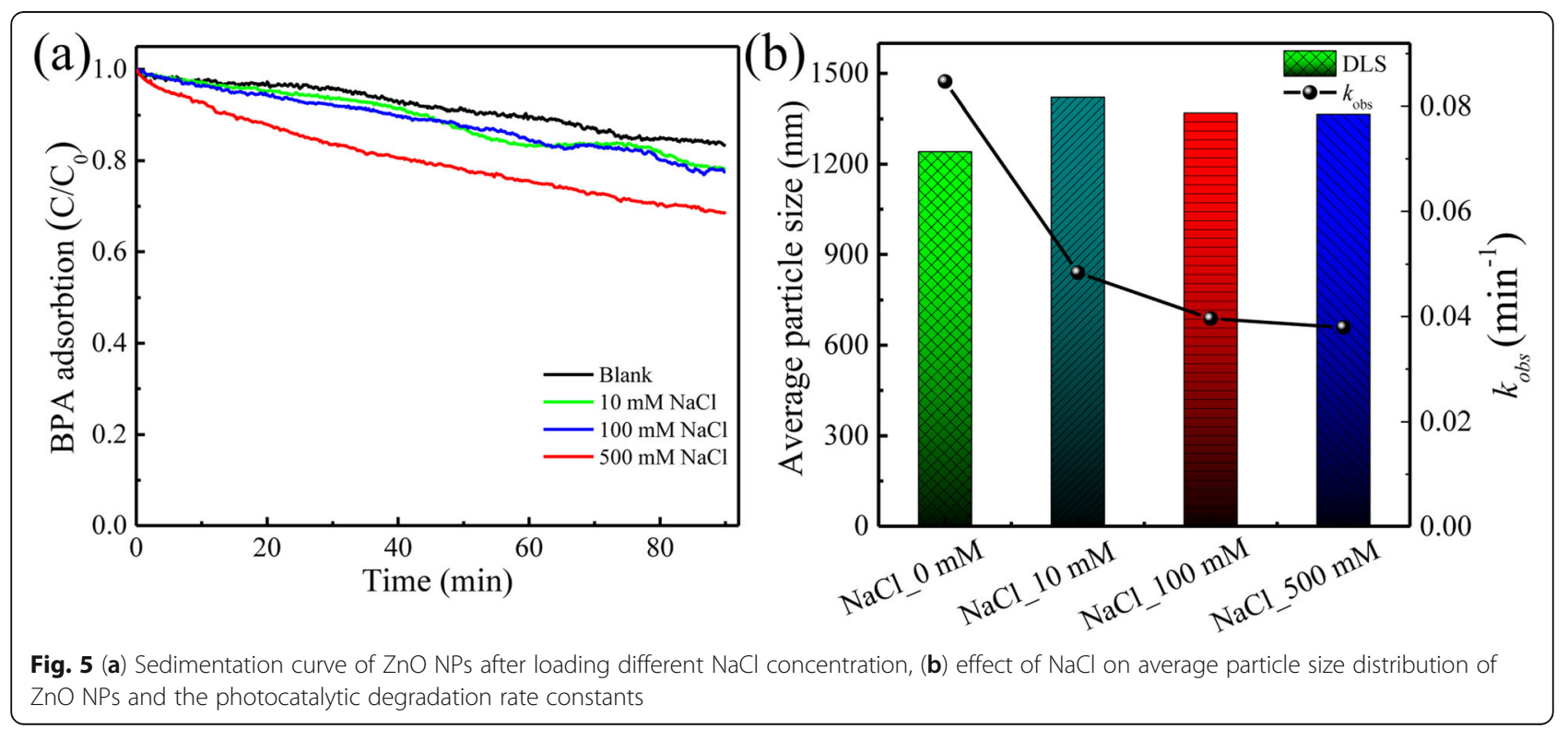



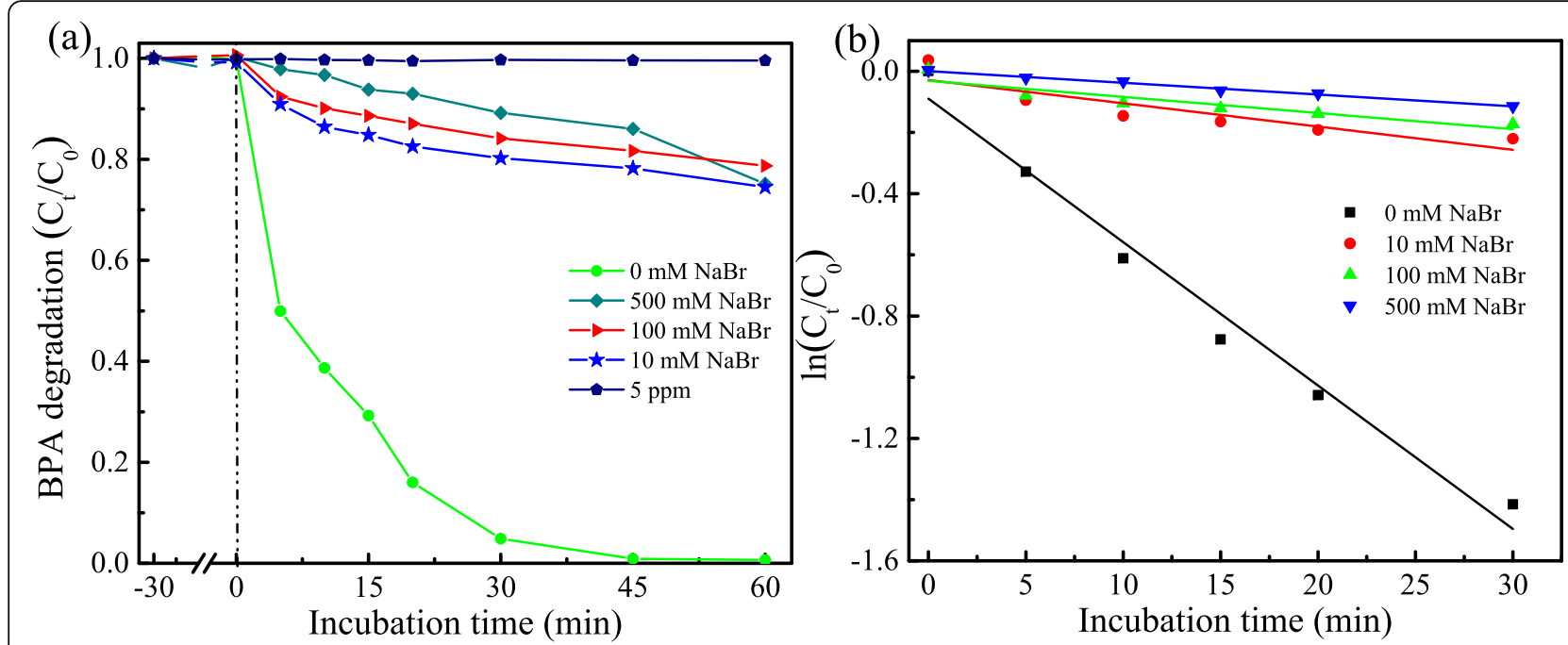

Fig. 6 (a) Effect of the $\mathrm{NaBr}$ concentration on the photocatalytic degradation of BPA under $365 \mathrm{~nm}$ UV light, (b) the plot of In (C/Co) vs irradiation time for the photocatalytic degradation of BPA with ZnO NPs under different $\mathrm{NaBr}$ concentrations

halide radical formation. This study of the inorganic ion effect (usually negative) over BPA photocatalytic degradation is found to be supporting the degradation process (in the presence of $\mathrm{NaCl}$ ), by $\mathrm{ZnO}$ NPs, hence providing a novel platform for better understanding of the inorganic ion-based wastewater treatment.

\section{Conclusions}

The photocatalytic degradation kinetic rate constant of BPA increased with the increase of $\mathrm{ZnO}$ NPs dosages from 10 to $100 \mathrm{mg} \mathrm{L}^{-1}$, with insignificant adsorption during $30 \mathrm{~min}$ dark experiment. An obvious aggregation was observed after aqueous dispersion of $\mathrm{ZnO}$ NPs, leading to formation of large particles, contrary to the commercial $20 \mathrm{~nm}$ particle size. The effect of halide ions during photocatalytic degradation of BPA was investigated using $\mathrm{NaCl}$ and $\mathrm{NaBr}$ salt solutions. $\mathrm{NaBr}$ salt solution restricts the BPA degradation due to aggregation and limited light adsorption capacity. The average hydrodynamic particle size of ZnO NPs increased around 139\%, leading to reduced rate of BPA up to $90 \%$ compared to the one without $\mathrm{NaBr}$. However, $\mathrm{NaCl}$ could slightly suppress the degradation rate of BPA around $50 \%$ by $500 \mathrm{mM} \mathrm{NaCl}$. The sedimentation curve reveals no significant change on the particle size and light absorbance efficiency, suggesting the relation between the rate constant and the average hydrodynamic particle size. Suppressed rate of BPA could be
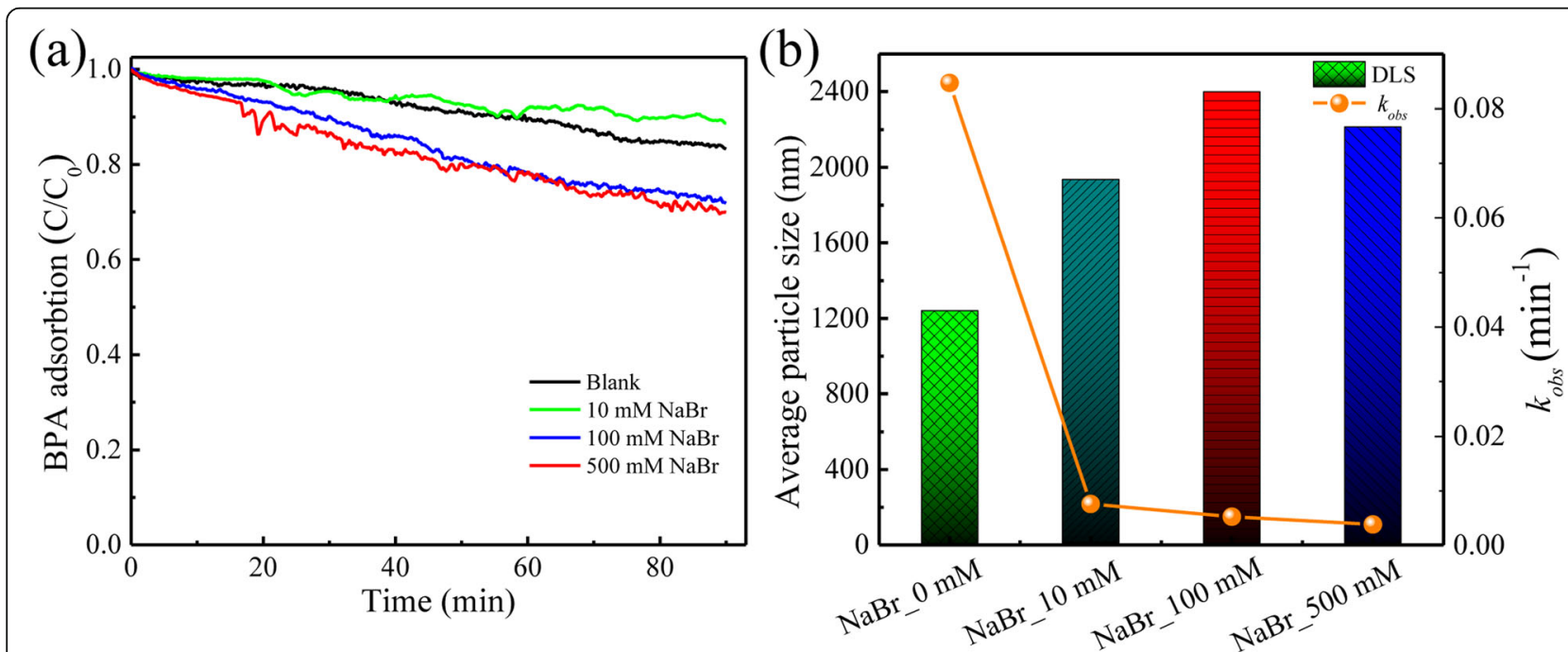

Fig. 7 (a) Sedimentation curve of ZnO NPs after loading different NaBr concentration, (b) effect of NaBr loading on average particle size distribution of ZnO NPs and the photocatalytic degradation rate constants 
anticipated due to competition between $\mathrm{NaCl}$ salt and BPA molecules. This study reveals the impact of $\mathrm{NaCl}$ and $\mathrm{NaBr}$ salt solution on BPA removal and provides an essential information to facilitate the remediation of inorganic ion-included wastewater in the future.

\section{Acknowledgments}

The authors gratefully acknowledge the financial support of the Ministry of Science and Technology, Taiwan, Ms. Chia-ying Chien in Instrumentation Center (National Taiwan University) for the assistance in TEM experiment. We appreciate the help from Mr. Bo-Yen Chen for his experimental work during dose and $\mathrm{pH}$ optimization. We thank the anonymous referees for reviewing this manuscript.

\section{Authors' contributions}

Yi-Chen Yang and Rama Shanker Sahu provide equal contribution for this paper. Yi-Chen Yang: Conducted experiment, analyzed data, and wrote the manuscript draft. Rama Shanker Sahu: designed some experiments, analyzed data and wrote the manuscript, and Yang-Hsin Shih: Conceptualize, design, and corrected the manuscript. All authors read and approved the final manuscript.

\section{Funding}

Yi-Chen Yang thanks her college student research funding from Ministry of Science and Technology, Taiwan.

\section{Availability of data and materials}

All data generated or analyzed during this study are included in the manuscript.

\section{Declarations}

\section{Competing interests}

The authors declare they have no competing interests.

Received: 12 April 2021 Accepted: 29 December 2021

Published online: 28 January 2022

\section{References}

1. Liu G, Hyotylainen T, Falandysz J. Toxicology and environmental characteristics of emerging pollutants. Ecotox Environ Safe. 2019;181:264.

2. Yang SQ, Cui YH, Liu YY, Liu ZQ, Li XY. Electrochemical generation of persulfate and its performance on 4-bromophenol treatment. Sep Purif Technol. 2018;207:461-9.

3. Chouhan S, Yadav SK, Prakash J, Swati, Singh SP. Effect of Bisphenol A on human health and its degradation by microorganisms: a review. Ann Microbiol. 2014:64:13-21.

4. Lee CC, Hsieh CY, Chen CS, Tien CJ. Emergent contaminants in sediments and fishes from the Tamsui River (Taiwan): their spatial-temporal distribution and risk to aquatic ecosystems and human health. Environ Pollut. 2020;258: 113733.

5. Huang $Y Q$, Wong CKC, Zheng JS, Bouwman $H$, Barra $R$, Wahlstrom $B$, et al. Bisphenol A (BPA) in China: a review of sources, environmental levels, and potential human health impacts. Environ Int. 2012;42:91-9.

6. Barboza LGA, Cunha SC, Monteiro C, Fernandes JO, Guilhermino L. Bisphenol $A$ and its analogs in muscle and liver of fish from the North East Atlantic Ocean in relation to microplastic contamination. Exposure and risk to human consumers. J Hazard Mater. 2020;393:122419.

7. Li AJ, Zhuang TF, Shi W, Liang Y, Liao CY, Song MY, et al. Serum concentration of bisphenol analogues in pregnant women in China. Sci Total Environ. 2020:707:136100.

8. Angeles LF, Mullen RA, Huang IJ, Wilson C, Khuniar W, Sirotkin HI, et al Assessing pharmaceutical removal and reduction in toxicity provided by advanced wastewater treatment systems. Environ Sci-Wat Res. 2020;6:62-77.

9. Dukkanci M. Sono-photo-Fenton oxidation of bisphenol-A over a $\mathrm{LaFeO}_{3}$ perovskite catalyst. Ultrason Sonochem. 2018;40:110-6.

10. Kaur B, Dulova N. UV-assisted chemical oxidation of antihypertensive losartan in water. J Environ Manage. 2020;261:110170.
11. Gui $L$, Jin HY, Zheng $Y$, Peng RC, Luo YB, Yu P. Electrochemical degradation of bisphenol A using different modified anodes based on titanium in aqueous solution. Int J Electrochem Sc. 2018;13:7141-56.

12. Bao T, Damtie MM, Hosseinzadeh A, Wei W, Jin J, Vo HNP, et al. Bentonitesupported nano zero-valent iron composite as a green catalyst for bisphenol A degradation: preparation, performance, and mechanism of action. J Environ Manage. 2020;260:110105.

13. Garcia-Becerra FY, Ortiz I. Biodegradation of emerging organic micropollutants in nonconventional biological wastewater treatment: a critical review. Environ Eng Sci. 2018;35:1012-36.

14. Lee JH, Kwak SY. Rapid adsorption of bisphenol A from wastewater by betacyclodextrin-functionalized mesoporous magnetic clusters. Appl Surf Sci. 2019:467:178-84.

15. Chmayssem A, Taha S, Hauchard D. Scaled-up electrochemical reactor with a fixed bed three-dimensional cathode for electro-Fenton process: application to the treatment of bisphenol A. Electrochim Acta. 2017;225:435-42.

16. Akbari S, Ghanbari F, Moradi M. Bisphenol A degradation in aqueous solutions by electrogenerated ferrous ion activated ozone, hydrogen peroxide and persulfate: applying low current density for oxidation mechanism. Chem Eng J. 2016;294:298-307.

17. Shih $\mathrm{YH}$, Chen $\mathrm{M}$. Effects of cation on dechlorination of pentachlorophenol by nanoscale Pd/Fe bimetallic particles. Sustainable Environment Research, 2010, 20: 333-339.

18. Shih YH, Tso CP, Tung LY, Rapid Degradation of Methyl Orange with Nanoscale Zerovalent Iron Particles, Journal of Environmental Engineering and Management, 2010; 20: 137-143.

19. Yang-hsin, Shih Meng-Yi, Chen Yuh-Fan, Su (2011) Pentachlorophenol reduction by $\mathrm{Pd} /$ Fe bimetallic nanoparticles: Effects of copper nickel and ferric cations. Applied Catalysis B: Environmental 105(1-2) 24-29 10.1016/j. apcatb.2011.03.024

20. Matsumura Y, Hosokawa C, Sasaki-Mori M, Akahira A, Fukunaga K, Ikeuchi T, et al. Isolation and characterization of novel bisphenol-A-degrading bacteria from soils. Biocontrol Sci. 2009;14:161-9.

21. Mella B, Benvenuti J, Oliveira RF, Gutterres M. Preparation and characterization of activated carbon produced from tannery solid waste applied for tannery wastewater treatment. Environ Sci Pollut R. 2019;26: 6811-7.

22. Hernandez-Abreu AB, Alvarez-Torrellas S, Agueda VI, Larriba M, Delgado JA, Calvo PA, et al. Enhanced removal of the endocrine disruptor compound Bisphenol A by adsorption onto green-carbon materials. Effect of real effluents on the adsorption process. J Environ Manage. 2020;266:110604

23. Shih YH, Chou SM, Lin CF, Sorption mechanisms of selected chlorinated volatile organic compounds in organoclays, Journal of Environmental Engineering and Management, 2010; 20: 161-168.

24. Mercante LA, Iwaki LEO, Scagion VP, Oliveira ON, Mattoso LHC, Correa DS. Electrochemical detection of bisphenol A by tyrosinase immobilized on electrospun nanofibers decorated with gold nanoparticles. Electrochem. 2021;2:41-9.

25. Park CM, Heo J, Yoon Y. Oxidative degradation of bisphenol A and 17 aethinyl estradiol by Fenton-like activity of silver nanoparticles in aqueous solution. Chemosphere. 2017:168:617-22.

26. Krajangpan S, Jarabek L, Jepperson J, Chisholm B, Bezbaruah A. Polymer modified iron nanoparticles for environmental remediation. Polym Prepr. 2008:49:921.

27. Ong CB, Ng LY, Mohammad AW. A review of $\mathrm{ZnO}$ nanoparticles as solar photocatalysts: synthesis, mechanisms and applications. Renew Sust Energ Rev. 2018;81:536-51.

28. Majumder S, Chatterjee S, Basnet P, Mukherjee J. ZnO based nanomaterials for photocatalytic degradation of aqueous pharmaceutical waste solutions a contemporary review. Environ Nanotechnol Monit Manage. 2020;14: 100386.

29. Wei-Szu, Liu Yu-Huei, Peng Chia-En, Shiung Yang-hsin, Shih (2012) The effect of cations on the aggregation of commercial ZnO nanoparticle suspension. Journal of Nanoparticle Research 14(12) 10.1007/s11051-0121259-9

30. Yu-Huei, Peng Chih-ping, Tso Yi-chun, Tsai Cheng-ming, Zhuang Yang-hsin, Shih (2015) The effect of electrolytes on the aggregation kinetics of three different $\mathrm{ZnO}$ nanoparticles in water. Science of The Total Environment 530 531183-190 10.1016/j.scitotenv.2015.05.059

31. Yu-Huei, Peng Yi-Chun, Tsai Chia-En, Hsiung Yi-Hsuan, Lin Yang-hsin, Shih (2017) Influence of water chemistry on the environmental behaviors of 
commercial ZnO nanoparticles in various water and wastewater samples. Journal of Hazardous Materials 322348-356 10.1016/j.jhazmat.2016.10.003

32. Wang YJ, Hu K, Yang ZY, Ye CL, Li X, Yan K. Facile synthesis of porous ZnO nanoparticles efficient for photocatalytic degradation of biomass-derived bisphenol A under simulated sunlight irradiation. Front Bioeng Biotech. 2021;:8616780.

33. Kazeminezhad I, Sadollahkhani A. Influence of pH on the photocatalytic activity of ZnO nanoparticles. J Mater Sci-Mater El. 2016;27:4206-15.

34. Lee KM, Lai CW, Ngai KS, Juan JC. Recent developments of zinc oxide based photocatalyst in water treatment technology: a review. Water Res. 2016;88: $428-48$

35. Zhao X, Du PH, Cai ZQ, Wang T, Fu J, Liu W. Photocatalysis of bisphenol A by an easy-settling titania/titanate composite: effects of water chemistry factors, degradation pathway and theoretical calculation. Environ Pollut. 2018:232:580-90.

36. Zerjav G, Albreht A, Vovk I, Pintar A. Revisiting terephthalic acid and coumarin as probes for photoluminescent determination of hydroxyl radical formation rate in heterogeneous photocatalysis. Appl Catal A-Gen. 2020;598: 117566.

37. Deokar PS, Cremaschi L. Effect of nanoparticle additives on the refrigerant and lubricant mixtures heat transfer coefficient during in-tube single-phase heating and two-phase flow boiling. Int J Refrig. 2020;110:142-52.

38. Choi K, Kang T, Oh SG. Preparation of disk shaped $\mathrm{ZnO}$ particles using surfactant and their PL properties. Mater Lett. 2012;75:240-3.

39. Sahu RS, Shih YH. Reductive debromination of tetrabromobisphenol A by tailored carbon nitride Fe/Cu nanocomposites under an oxic condition. Chem Eng J. 2019:378:122059.

40. Sahu RS, Bindumadhavan K, Doong RA. Boron-doped reduced graphene oxide-based bimetallic $\mathrm{Ni} / F e$ nanohybrids for the rapid dechlorination of trichloroethylene. Environ Sci-Nano. 2017;4:565-76.

41. Trandafilovic LV, Jovanovic DJ, Zhang X, Ptasinska S, Dramicanin MD. Enhanced photocatalytic degradation of methylene blue and methyl orange by ZnO:Eu nanoparticles. Appl Catal B-Environ. 2017;203:740-52.

42. Zeng Y, Guo N, Xu XJ, Yu Y, Wang QY, Wang N, et al. Degradation of bisphenol a using peroxymonosulfate activated by $\mathrm{WO}_{3} @ \mathrm{MoS}_{2} / \mathrm{Ag}$ hollow nanotubes photocatalyst. Chemosphere. 2019;227:589-97.

43. Chen QF, Wang H, Luan QR, Duan R, Cao XZ, Fang YF, et al. Synergetic effects of defects and acid sites of 2D-ZnO photocatalysts on the photocatalytic performance. J Hazard Mater. 2020;385:121527.

44. Saffari R, Shariatinia Z, Jourshabani M. Synthesis and photocatalytic degradation activities of phosphorus containing $\mathrm{ZnO}$ microparticles under visible light irradiation for water treatment applications. Environ Pollut. 2020; 259:113902.

45. Sahu RS, Shih YH, Chen WL. New insights of metal free 2D graphitic carbon nitride for photocatalytic degradation of bisphenol A. J Hazard Mater. 2021; 402:123509.

46. French RA, Jacobson AR, Kim B, Isley SL, Penn RL, Baveye PC. Influence of ionic strength, $\mathrm{pH}$, and cation valence on aggregation kinetics of titanium dioxide nanoparticles. Environ Sci Technol. 2009;43:1354-9.

47. Fatisson J, Domingos RF, Wilkinson KJ, Tufenkji N. Deposition of $\mathrm{TiO}_{2}$ Nanoparticles onto silica measured using a quartz crystal microbalance with dissipation monitoring. Langmuir. 2009;25:6062-9.

48. Liu W, Yang Q, Wang Z, Lv XF, Yang ZL. Photocatalytic degradation of trichloroethylene over BiOCl under UV irradiation. Appl Organomet Chem. 2018;32:e4354

49. Wang P, Yang SY, Shan L, Niu R, Sha XT. Involvements of chloride ion in decolorization of Acid Orange 7 by activated peroxydisulfate or peroxymonosulfate oxidation. J Environ Sci-China. 2011;23:1799-807.

50. Qu JG, Chen RY, Dong X, He JX. Effect of $\mathrm{NaCl}$ concentrations on the photodecoloration of reactive azo-dyes and their cotton dyeings. Text Res $\mathrm{J}$. 2014:84:2140-8.

51. Toledo IB, Ferro-Garcia MA, Rivera-Utrilla J, Moreno-Castilla C, Fernandez FJV. Bisphenol A removal from water by activated carbon. Effects of carbon characteristics and solution chemistry. Environ Sci Technol. 2005;39:6246-50.

52. Garcia-Espinoza JD, Zolfaghari M, Nacheva PM. Synergistic effect between ultraviolet irradiation and electrochemical oxidation for removal of humic acids and pharmaceuticals. Water Environ J. 2020;34:232-46.

\section{Publisher's Note}

Springer Nature remains neutral with regard to jurisdictional claims in published maps and institutional affiliations.

\section{Ready to submit your research? Choose BMC and benefit from:}

- fast, convenient online submission

- thorough peer review by experienced researchers in your field

- rapid publication on acceptance

- support for research data, including large and complex data types

- gold Open Access which fosters wider collaboration and increased citations

- maximum visibility for your research: over $100 \mathrm{M}$ website views per year

At BMC, research is always in progress.

Learn more biomedcentral.com/submissions 